\title{
Pedro Juan Núñez y la enseñanza de Hermógenes *
}

\author{
FERRAN GRAU CODINA \\ Universitat de València-Estudi General \\ ferran.grau@uv.es
}

\section{Evolución de las concepciones sobre la retórica de Pedro Juan Núñez}

La importancia y difusión de la retórica de Hermógenes en el s. XVI, en un primer momento a través de la mediación de los Rhetoricorum libri $V$ de Jorge de Trebisonda y más tarde gracias a las traducciones al latín, es ya un hecho reconocido y probado, así como la posible influencia que pudo tener en la creación literaria del s. XVI, tanto en lengua vulgar como en latín. También parece predominar el carácter ecléctico de la mayor parte de autores de retóricas del s. XVI, quienes, utilizando como base una determinada tradición retórica, suelen integrar también en ese marco otras teorías con la finalidad explícita de armonizarlas o, como en el caso de Núñez, que sigue en esto la huella de Trebisonda, introduciendo una ejemplificación y aplicación a la literatura latina. Pedro Juan Núñez (1529-1602) fue, por lo tanto, uno de los autores que contribuyeron a la difusión y enseñanza en suelo hispano de la retórica de Hermógenes, que adaptó y llevó a la imprenta en tres ocasiones ${ }^{1}$. Sin embargo, el punto de partida de sus publicaciones retóricas es un tratado de inspiración completamente ramista: las Institutiones Oratoriae ${ }^{2}$. En los 26 años que separan las Institutiones Oratoriae (1552) y la primera edición de las Institutiones Rhetoricae (1578) no existe ninguna otra publica-

* Este trabajo se enmarca en el proyecto de investigación "Estudios de textos latinos humanísticos de autores valencianos de los s. XVI al XVIII. Relevancia de los mismos en el contexto europeo" (PB 97-1389 Ministerio de Educación y Cultura), dirigido por el Dr. Jordi Pérez Durà.

1 Las tres en Barcelona en 1578, 1585 y 1593. Una edición de esta retórica se encuentra en F. GRAU, "Las retóricas de Pedro Juan Núñez (ediciones y manuscritos)". Tesis doctoral, Universitat de València, 1994.

2 Institutiones Oratoriae, collectae methodicws, ex institutionibus prioribus Audomari Talaei, Authore Petro Ioanne Nunnesio Valentino. Valentiae, Per Ioannem Mey Flandrum, 1552, también editadas en mi tesis, ya citada. 
ción impresa de carácter retórico ${ }^{3}$. ¿Cuál fue la evolución, el cambio que llevó a Núñez de una concepción ramista a la retórica de Hermógenes? Además del propio carácter de sus Institutiones, de clara inspiración ramista declarada en su título, sus opiniones sobre la retórica en tanto que ars, su función, sus partes y el lugar que debe ocupar en el currículum educativo, sobre todo en relación con la dialéctica, quedan plasmadas fundamentalmente en otra de sus obras, el Commentarius in constitutionem artis Dialecticae de 1554, publicado junto a la Oratio de causis Aristoteleae y el Liber de constitutione artis Dialecticae en Valencia. Esta concepción puede resumirse en los siguientes puntos:

1. Los principios pedagógicos de adquisición de las artes son natura, ars y exercitatio ${ }^{4}$.

2. Clara delimitación de las competencias de las diferentes artes, quedando la retórica reducida a elocutio, o lo que es lo mismo, ornatus. Dependencia no obstante de la dialéctica y la filosofía moral ${ }^{5}$.

3. El orden de aprendizaje de las disciplinas debe claramente ser primero la grammatica, segundo la dialectica y tercero la rhetorica ${ }^{6}$.

4. La retórica, como la dialéctica, son facultates, no scientiae, en tanto que son generales y propedéuticas y no conocimientos concretos y particulares ${ }^{7}$.

5. Exclusión de la retórica de memoria y pronuntiatio ${ }^{8}$.

${ }^{3}$ Excluyendo los Apposita M. T. Ciceronis, Valentiae, 1556, (reeditada corregida con el título de Epitheta, en Venecia 1570, Lyon y Colonia 1571 y Barcelona 1588) que son obras de apoyo para la imitación de Cicerón.

${ }^{4}$ Nam si quis obseruet diligenter et accurate quomodo omnes homines, natura duce, disputent, qui bene et qui male haec faciunt, tum ad praecepta artis se conferat, quibus usus errores naturae emendet, deinde in iis se exerceat ad artem confirmandam, is certe perfectam facultatem Dialecticae consequeretur. (Commentarius, ff. 61r-61v). Vid. Pilar Barbeito Diez, Pedro Juan Núñez, humanista valenciano, Valencia: Biblioteca valenciana, 2000, pp. 281-285.

${ }^{5}$ Grammatica quidem circa proprietatem sermonis, Rhetorica circa ornatum, Dialectica circa tractationem, quae inuentione et dispositione perficitur. (...) Aristoteles quidem in Rhetoricis tradidit praecepta inueniendi et disponendi, et in Dialecticis, quamquam quo loco scribit rhetoricam constare ex Dialectica et Politica uidetur aperte sentire Rhetoricam accepisse praecepta inueniendi et disponendi ex Dialectica. Morum autem et perturbationum explicationem ex Politica, id est, ex philosophia morali, nam totam philosophiam moralem Politicam uocat. (Commentarius, ff. 58v-59r).

6 Ars imitatur naturam, ordo autem naturae hoc postulat, ut primum loquamur, deinde utamur ratione, postremo sententias et uerba ornemus, quare primum docenda est Grammatica, quae instruit sermonem; deinde Dialectica, quae rationem informat; postremo Rhetorica, quae sententias et uerba dicendo ornat. (Commentarius, f. $55 \mathrm{v}$ ).

${ }^{7}$ Prima significatione Logica non est scientia, ut Aristoteles scribit primo Rhetorico his uerbis: Qui aut Dialecticam, aut Rhetoricam non ut facultates, sed ut scientias tractare conatur, imprudens naturam ipsarum tollit, quia in scientias rerum subiectarum transfert, sed non solum rationum. Quo loco negat aperte Dialecticam et Rhetoricam scientias esse, quia omnis scientia circa rem certam subiectam uersatur, ut Aristoteles demonstrat in Posterioribus. Dialectica autem et Rhetorica, imo tota Logica, circa res omnes uersantur, non circa certum genus rerum. (Commentarius, ff. 67v-68r).

${ }^{8}$ Nam actio, quae ultima pars affertur, non tam oratorum est, quam histrionum propria, et Orator suum nomen sine hac tuebitur, ut Isocrates, qui domesticam aluit dicendi gloriam. Memoria communis est omnium artium, si facultas est animi nostri. (Commentarius, f. 84v). 
Pedro Juan Núñez, por lo tanto, en su primera etapa, y concretamente en 1554 todavía muestra un gran influencia de Petrus Ramus, también en retórica, pues comparte, si no todos y cada uno de sus postulados, sí una concepción de la retórica claramente deudora de éste. Sin embargo se observa un afán por encontrar siempre una base en los autores antiguos para tales concepciones, principalmente en Aristóteles, y a pesar de las afinidades con Ramus, Núñez siempre manifestó sus discrepancias en lo que consideró adecuado ${ }^{9}$.

Estas concepciones, en cuanto tales, no parece que hayan variado tanto con el paso de los años en algunos aspectos. Por ejemplo, los principios pedagógicos siguen siendo los mismos como puede leerse en la segunda edición de sus Institutionum Rhetoricarum libri $V$ donde incluye un capítulo al final de la obra titulado De exercitatione rhetorica que da comienzo precisamente con las siguientes palabras: Eloquentiae, ut ceterarum artium facultas, tribus partibus perficitur: natura, arte, et exercitatione ${ }^{10}$. Tampoco aceptó nunca la inclusión de la actio ni de la memoria como parte de la retórica ${ }^{11}$. E incluso en los Prolegomena de sus Institutionum Rhetoricarum libri $V$ admite el carácter general de la retórica, si consideramos exclusivamente la elocución, aunque inmediatamente estima que su terreno propio es el de la causa ciuilis ${ }^{12}$. Otras reflexiones teóricas sobre el papel, función o partes de la retórica semejantes a las del Commentarius no vuelven a encontrarse hasta su De recta atque utili ratione conficiendi curriculi Philosophiae, Barcelona, 1594, donde, en efecto, pueden apreciarse cambios profundos en su concepción. Por ejemplo, aunque se afirma que sus contenidos, como en 1554, proceden en buena parte de la dialéctica y la filosofía moral, la retórica navega ahora prácticamente sin entidad, puesto que lejos de ser su parte propia, general y propedéutica, el ornatus, nos hallamos ante una disciplina que solo pingui Minerva aborda su cometido casi como una usur-

9 De hecho, aunque se reconoce como el primer introductor de Ramus en Valencia, ya muestra los límites de su adhesión: Quamobrem etsi primus in schola Valentina Rami sectatorem professus sum, non ita accipiendum esse illud puto, ut integrum mihi non esset a sententia illius discedere, cum locus et tempus postularent. Nullius enim addictus iurabo in uerba magistri, neque patiar ueritati, quae una in omni tempore et loco dominatur, hominum autoritatem praeponderare. Sed haec alias. (Commentarius, f. 92v). Sobre la cuestión concreta de la dialéctica vid. Pilar BaRbeito Diez, "¿El Brocense o Pedro Juan Núñez? Sobre la introducción en España de la dialéctica ramista”, en J. M. "MAESTRE - J. PASCUAL - L. Charlo (eds.), Humanismo y pervivencia del mundo clásico. Homenaje al profesor Luis Gil, 1I.2. Cádiz, 1997, pp. 735-746.

${ }^{10}$ Institutionum Rhetoricarum libri quinque, pp. 415=443 (cito por la página de mi edición y al lado la equivalencia en la edición de 1585 para facilitar su consulta).

11 Instrumenta oratoris aut sunt naturalia, aut studio parta. Naturalia quidem ingenium, iudicium, memoria, uox, latera, decor, studium, et alia huiusmodi, quae etsi mediocria natura data sint oratori, maximo tamen ei erunt ornamento, possuntque eadem arte multum adiuuari. (Institutionum Rhetoricarum libri $V$, pp. $65=2$ ). Esta insistencia en la exclusión de la pronuntiatio, aludida aquí en los términos uox, latera, decor, es tanto más llamativa cuanto sus Institutiones Oratoriae de 1552, aunque la excluyen, se basan en la edición de la retórica de $\mathrm{O}$. Talon de 1548 , que ya incluye esta parte.

12 Materia subiecta oratori, si elocutronem spectes, latissime patet, nam habet quiddam necessarium fere in omni doctrina; alioqui materia illi subiecta erit potissimum causa ciuilis, id est, quae in aliqua societate ciuili exercetur ut in iudiciis et accusatio. (Inst. Rhet. lib. V, pp. 65=1). 
padora ${ }^{13}$. Por otra parte, hay que resaltar que aunque reconoce la superioridad de Hermógenes en la enseñanza de la retórica para producir oradores más completos y agudos, sin embargo recomienda la retórica de Aristóteles como introducción al estudio de la filosofía de este autor ${ }^{14}$.

Por ello, podemos establecer su concepción de la retórica en 1594 en los siguientes puntos:

1. Los principios pedagógicos siguen siendo los mismos: natura, ars, exercitatio.

2. No es tan riguroso en cuanto a la distinción entre las artes, de modo que la especificidad de la retórica queda reducida a las res ciuiles, aun admitiendo la amplitud de aplicación de la elocutio. Sin embargo, la dependencia de la dialéctica y la filosofía moral hace que su función se reduzca a una especie de tratamiento general, poco riguroso y divulgativo.

3. Propone otro orden en la enseñanza de las artes: la retórica debe enseñarse antes que la dialéctica, puesto que hay que conocer los ejemplos de historiadores, poetas y oradores ${ }^{15}$.

4. Hermógenes es preferible para la formación del orador, pero recomienda el estudio de la retórica de Aristóteles como introducción al estudio de su filosofía ${ }^{16}$.

5. Sigue excluyendo memoria y pronuntiatio como partes de la retórica.

En mi tesis establecía, en consonancia con J. F. Alcina, unas motivaciones sobre la preferencia o el paulatino deslizamiento en la enseñanza de la retórica desde un enfoque predominantemente elocutivo a la retórica de Hermógenes, además de considerar, que en su práctica docente, combinara ambas tradiciones ${ }^{17}$. Más allá de los peligros de persecución que podía comportar seguir declaradamente en algún aspecto la doctrina de Ramus, lo

13 Iudicio Aristotelis post logicam et philosophiam moralem disci oportere, quia Aristoteles libro 1 Rhetoricorum scribit Rhetoricam quasi stolonem quendam ex logica et philosophia morali pullulasse. Est ita quidem, ut dicis, sic tamen ex utraque profectam artem bene dicendi affirmat, ut quod illae exquisite persequuntur, Rhetorica, tantum typo et pingui Minerua complectatur... (De recta atque utili ratione, f. $13 \mathrm{v}$ ).

14 Nam de Rhetoricis, quanuis conemur alibi autem Hermogenis multo praestabiliorem esse docere, quod et oratorem expeditiorem ad dicendum atque acriorem reddat, tamen, quoniam Rhetoricam ad intelligentiam Philosophiae ac praesertim Aristotelicae, requirimus, non est dubium quin eiusdem Aristotelis libri sint multo fructuosiores. (De recta atque utili ratione, ff. 19r-19v).

15 Barbeito, Pedro Juan Núñez, p. 294: “Al adoptar esta nueva disposición Núñez se aproxima ahora a los planteamientos de Ramos - que también propugnaba un conocimiento de la retórica previo al de la dialéctica -, autor con el que, curiosamente, no coincidía en cambio en su etapa ramista".

16 No hay que olvidar que Núñez como filósofo fue aristotélico. Para la enseñanza de la Poética de Aristóteles por parte de Núñez vid. J. Fr. Alcina, "El comentario a la Poética de Aristóteles de Pedro Juan Núñez", Excerpta Philologica. Antonio Holgado Redondo Sacra 1.1. Cadiz, 1991, pp. 19-34.

17 Entre ellas considera J. Fr. Alcina que el hermogenismo "está en la base de varios conceptos ramistas, entre otros el de Methodos; junto a esto hay que recordar que el divulgador más importante de Hermógenes en el XVI es Johann Sturm, que fue también maestro de Ramus en 
cierto es que Hermógenes ofrece una especie de tercera vía, una salida al problema planteado entre los límites de competencias entre retórica y dialéctica, con una inventio representada básicamente por la teoría de los status ajustada al género forense (básicamente el judicial, pero extensible también al deliberativo), una retórica alternativa que incluía el concepto de methodus en su doble vertiente de methodus doctrinae y methodus prudentiae tan importante en la dialéctica ramista, y por otra parte, una elocutio muy elaborada en el libro de ideis en que se aplica el método de división en consonancia con los principios ramistas. Sin embargo, la elección de Hermógenes es perfectamente coherente con los principios metodológicos seguidos y aplicados por Pedro Juan Núñez tanto en 1554 como en 1594, es decir, durante toda su vida. Veamos por qué.

P. Barbeito ha hecho notar la divergencia del ramismo por parte de Núñez en fecha tan temprana como 1554 para una cuestión fundamental, la de la methodus ${ }^{18}$. Núñez parece tener muy clara la especificidad de cada arte y que cada una requiere un método particular, y esto es lo que deja ver su práctica como docente: sin embargo esta idea la formula ya en 1554, en sus Institutionum Physicarum libri IV, con su teoria de la paedia generalis y la paedia specialis. ¿En qué consisten una y otra? La paedia generalis "se identifica con el aristotélico método analítico", la paedia specialis es el método propio de cada disciplina. Sin embargo, ambos proceden desde lo general a lo particular, definición que coincide con la dada en el De constitutiones artis dialecticae libellus para la methodus doctrinae ${ }^{19}$. En 1594, en el De recta atque utili ratione conficiendi curriculi Philosophiae, mantiene la distinción ${ }^{20}$, por lo tanto puede afirmarse que estos constituyen los principios metodológicos sostenidos por Núñez durante toda su vida, y en la elección de Hermógenes es consecuente con sus principios ya que este autor constituye la mejor expresión de esa paedia specialis de la retórica, ya que adapta sus preceptos a la especificidad de la retórica como causa civilis ${ }^{21}$.

La retórica de Hermógenes incluía, además, en todas sus partes, dos tipos de methodus, primero el de la división clara de cara a la enseñana, pero

París"; vid. J. Fr. Alcina, "Los inicios del ramismo en España" en J. Pérez DuRÀ - J. M. a EsteLLÉS (eds.), Los humanistas valencianos y sus relaciones con Europa: de Vives a Mayans, Valencia, Ajuntament de València, 1998, pp. 117-136 (esp. pp. 122-131).

18 Barbeito, que añaliza muy bien lo que ella denomina "abandono del método ramista", concluye que "Núñez abandona de manera definitiva la división en methodus doctrinae y methodus prudentiae, de la que jamás volverá a hacer mención", aunque un poco más arriba había advertido de que "procede también a asimilar la distinción paideia generalis / paideia specialis con la división ramista del método en methodus doctrinae / methodus prudentiae"; BARBEITO. Pedro Juan Núñez, p. 171.

19 Compárense ambas: nempe a generalioribus ad specialiora progrediendum est, ut res facilius comprehendantur, non uicissim, ne eandem disputationem saepe repetere cogamur, (Inst. Phys. lib. IV. Ratio methodi, s. f.). Methodus doctrinae, est collocatio a generalioribus ad specialiora progrediens; per quam unaquaeque res facilius percipi possit. (Libellus, f. $52 \mathrm{v}$ ).

${ }^{20}$ Paedia igitur duas species facit Aristoteles libro I De partibus animalium, unam generalem, alteram specialem: generalis nomine accipiunt prisci Peripatetici Logicam atque eius methodos in commune; specialis uero eandem logicam cum alicui arti aut rei subiectae proprie ea accommodatur. (De recta atque utili ratione... f. 20r).

21 Inst. Rhet. lib. V, p. $65=1$. 
en especial en el de statibus y en el de ideis, donde esta división se aplica explicítamente; el segundo es la methodus prudentiae que constituye el último de los cinco libros del corpus hermogeniano y que consiste, como la methodus prudentiae ramista, "ut intelligeremus quae oratio oratori esset accommodata pro circunstantiarum uarietate" (Inst. Rhet. lib. V, p. 386=406).

Parece conveniente matizar, pues, el alejamiento de Núñez respecto de Ramus. Por una parte, ya desde 1554, Núñez mantiene una independencia de criterio respecto de Ramus, e incluso un rechazo, casi por despecho, al denunciar que éste se ha apropiado de un método que para Núñez ya se encuentra en Aristóteles ${ }^{22}$. Por otra parte, se mantiene una constante en ciertas nociones, como la de methodus en Hermógenes, e incluso los conceptos ramistas de genesis y analysis correspondientes a la exercitatio que se permite recordar en la retórica de $1585^{23}$. Parecería que aunque Núñez se decante abiertamente por Aristóteles, no pudiera desprenderse de la huella dejada en él por algunas nociones ramistas ${ }^{24}$.

\section{La docencia y enseñanza de Hermógenes}

Contamos además con un buen número de manuscritos que nos acercan a lo que debía ser la enseñanza concreta de la retórica en las aulas de Pedro Juan Núñez. Los manuscritos que contienen obra retórica y que hemos manejado son los siguientes: Institutionum rhetoricarum artium a doctore Petro Johanne Nunnesio Valentino, traditae ab eodem ex diversis et optimis scriptoribus collectae anno a natali Domini MDLXXIII (ff. 19-37) (ms. 69 fons Sant Cugat del Archivo de la Corona de Aragón en Barcelona, en adelante ms. $69 \mathrm{StC}$ ); In Aphtonii progymnasmata dictata accuratissima et suis omnibus numeris absoluta (ff. 292-363) (ms. 1185 de la Biblioteca de la Universidad de Barcelona, en adelante ms. 1185 BUB); Institutiones Oratoriae ex variis scriptoribus ac praesertim ex Hermogene auctore Petro I. Nunnesio Valentino (ff. 2-155) (ms. 9153 de la Biblioteca Nacional de Madrid, en adelante ms. 9153 BN); De elocutione (ff. 25-36) y Ex institutionibus oratoriis Petri Johannis Nunnesii (ff. 37-54) (ms. 1657 de la Biblioteca de Catalunya, en adelante ms. $1657 \mathrm{BC})^{25}$. Es a través de estos como puede observarse o bien la incorporación de la retórica de Hermógenes a esta enseñanza, o bien

22 Reprehendendus quoque P. Ramus, qui se primum autorem methodi doctrinae et prudentiae professus est, cum Aristoteles huius sententiae primus autor et inuentor fuerit, sed Ramus ut credo, tanquam callidus fur, mutatis nominibus, ceu signis mutatis, culpam se huius criminis uitaturum fuisse existimauit. (Institutionum Physicarum libri IV, s. f.).

${ }^{23}$ Nam illa genesis, et analysis, quae addunt alii, peregrinis tantum nominibus notata sunt. Res autem eadem genesi namque nouum opus conficimus, analysi uero confectum ab alio opus ipsi reteximus. (Inst. Rhet. lib. V, p. 431=463).

24 Podemos recordar aquí las palabras de Gregorio Mayans: "Pero el maestro Núñez afectó tanto ser aristotélico, que su mayor conato parece mostrar que no lo fue, como quien estava arrepentido de aver seguido algún tiempo las novedades de Pedro Ramos." G. MaYans, Pensamientos Literarios, en Obra Completa, vol. I, Antonio Mestre (ed.), Valencia, 1984, p. 248.

25 Todos ellos transcritos en mi tesis. Habría que añadir las Institutiones oratoriae (ff. 1-23) (ms. 62-125) de la Biblioteca Capitular de la Seo de Zaragoza, que no he consultado. 
su enseñanza en las aulas en combinación con otras teorías vinculadas sobre todo a los géneros epistolares, de los que se conservan un buen número de textos también manuscritos. Aquí vamos a tener en cuenta, sobre todo, el ms. $69 \mathrm{StC}$ y el ms. $9153 \mathrm{BN}^{26}$.

Veamos el primero de ellos, las Institutiones Rhetoricarum artium de 1573 (ms. $69 \mathrm{StC}$ ). Este manuscrito, el único datado, contiene los apuntes que posiblemente tomaba al dictado un alumno asistente a las clases de Pedro Juan Núñez. En el primer párrafo del manuscrito enumera Núñez los géneros de discursos, asociando a ellos conceptos de orden muy práctico, normalmente relacionados con el género epistolar y que a lo largo del manuscrito trata con detalle. Así, al discurso panegírico, o "exornativo" como aquí lo denomina, que versa sobre la alabanza y el vituperio, se asocia la gratiarum actio y la gratulatio. Al discurso deliberativo, que versa sobre la persuasión y la disuasión, se asocia la petitio y la consolatio. Al género judicial que atañe a la defensa y acusación, se asocia la conquestio y la excusatio. Estamos ante un manuscrito que trata exclusivamente de la inventio, y por lo tanto sobre las partes del discurso que curiosamente establece en tres: exordium, confirmatio y peroratio. La exclusión de la narratio, que no hallamos en ningún otro manuscrito ni impreso de P. J. Núñez, la justificará más adelante, antes de dar comienzo al tratamiento de la confirmatio ${ }^{27}$

En primer lugar se ocupa del exordio en general, de sus tipos y la manera de ilustrarlos, utilizando para ello ejemplos de los discursos de Cicerón (f. 19r.-19v.); a continuación se ocupa del exordio únicamente del género "exornativo" y de sus formas de la gratiarum actio y la gratulatio (ff. 19v-20r); y en tercer lugar enumera hasta dónde alcanzan los exordios de todos los discursos y demás obras de Cicerón (ff.20r-21v).

Desde el f. $21 \mathrm{v}$. hasta el $24 \mathrm{r}$. trata sobre la confirmatio en general, que divide en dos partes: ratio generalis y propria. La ratio generalis se divide a su vez en cuatro partes: 1) los puntos principales o capita que suelen proponerse en las causas y cómo se proponen, 2) los lugares de donde se sacan los razonamientos para probar los capita, 3) con qué tipos de argumentos se confirman los razonamientos, y 4) la manera de pulir los argumentos para llevarlos a la perfección. En esta división se deja ver ya una cierta influencia

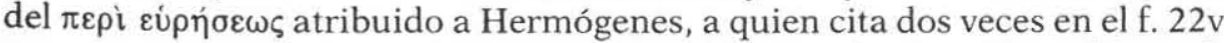
y que se corresponde con los contenidos del capítulo De ratione dilatandi inuenta argumenta de las Inst. Rhet. lib. V, p. $255=239^{28}$.

A partir del f. 23v hasta el 30v se ocupa de la confirmatio en el género "exornativo", en el que define la laus y explica cómo amplificarla; pasa enseguida a tratar la laudatio de las personas, que trata con alguna extensión,

${ }^{26}$ De la enseñanza de los progymnasmata me he ocupado en F. GRAU, "The teaching of the Progymnasmata of Pedro Juan Núñez (Valencia 1529-1602)", Advances in the History of Rhetoric: Disputed and Neglected Texts in the History of Rhetoric 1/1, 1997, 25-32.

${ }^{27}$ Ex iis efficitur, neque narrationem, neque propositionem, ab exordio euelli opportere quia, $u t$ docet Aristoteles, in exordio nihil aliud propositum est, quam explicare quid sit id, de quo sumus dicturi, quod est proprium propositionis et tamen quanuis aliis locis possit interponi (f. $21 \mathrm{v}$.).

${ }_{28}^{28}$ Parabolam appellamus cum Hermogene id quod plerumque ita fieri solet, ut si doceas parentes colendos esse quia bellua suos quoque parentes diligunt. Exemplum uero proprie appellatur $a b$ Hermogene quod ex re gesta, aut ex re dicta petitur... (f. 22v). 
detallando todos los puntos y lugares por los que se puede realizar (ff. $24 \mathrm{v}$ $27 \mathrm{r}$ ) y añade un capítulo sobre la peroratio laudationis (f. 27v); enseguida pasa a la laudatio de las ciudades (ff. 27v.-29r.), a un excurso sobre los loci a uirtutibus (f. 29r-v), a la laudatio de animales y plantas (f. 29v), de hazañas y héroes (f.29v) y de las artes (ff.29v-30r) ${ }^{29}$. A continuación se ocupa de la confirmatio en la gratiarum actio y la gratulatio (ff. 30r-30v).

Entre los ff. $30 \mathrm{v}-32 \mathrm{r}$ se refiere el comienzo de la peroratio en los discursos de Cicerón y una breve indicación sobre la peroratio en general que cierra esta parte.

Hasta el final se ocupa de las diferentes partes de la oratio, es decir, exordium, confirmatio y peroratio en los demás géneros, primero en el deliberativo en general (ff.32v-33v) en el que vuelve a citar a Hermógenes ${ }^{30}$, después en la petitio (f. $33 \mathrm{v}-34 \mathrm{r}$ ) y en la consolatio (ff. $34 \mathrm{r}-35 \mathrm{r}$ ), y por último en el género judicial, del que solo trata en sus partes de la expostulatio (ff. $35 \mathrm{r}$ 36r), y de la excusatio (ff. 36r-37r).

Puede observarse claramente una desproporción en el tratamiento del género "exornativo" y los demás, hecho que nos ilustra dónde pone el énfasis la práctica docente de Núñez en relación con la rétorica, no dirigida a una discusión teórica, sino a unos ejercicios prácticos relacionados con usos habituales, como la gratulatio, petitio, etc. y con indicación de hasta dónde llegan los exordios en las obras de Cicerón y dónde comienzan las peroraciones, con el objeto, a mi entender, de facilitar el análisis de los discursos de este autor para una posterior imitación.

En el segundo manuscrito, las Institutiones Oratoriae ex uariis scriptoribus ac praesertim ex Hermogene auctore Petro Ioanne Nunnesio Valentino anno (ms. 9153 Biblioteca Nacional), no aparece el año, pero por su contenido puede que se trate de un texto posterior a 1573, y quizás un poco anterior a la primera edición de las Institutiones Rhetoricae de $1578^{31}$, aunque tampoco puede descartarse que sea posterior. En cualquier caso, nos encontramos en él con un contenido de procedencia claramente hermogeniana, ya que se tratan los status y las ideae, con otros más tradicionales coincidentes en parte con el ms. 69 StC y en parte con el ms. 1185 BUB. Veamos sus contenidos.

En las primeras páginas del manuscrito se definen las funciones del orador en los mismos términos que en las Institutiones Rhetoricae impre-

29 Estos capítulos sobre la laudatio en que Núñez trata hasta el mínimo detalle són los que volvemos a encontrar en las Institutiones oratoriae del ms. 9153 de la Biblioteca Nacional y en los In Aphthonii Progymnasmata del ms. 1185 de la Biblioteca de la Universidad de Barcelona.

${ }^{30}$ Ad utilitatem refertur ab Hermogene id quod necessarium, quod tantum discrepat ab utili, quatenus utile locum reliquit deliberationi, necessarium uero omnem incidit deliberationem (f. 33r). Estos loci se encuentran mencionados en el progymnasma de la confirmatiuncula y el status negotialis de Hermógenes en la versión de Núñez.

31 En esta edición se dice en la dedicatoria a la universidad de Valencia las siguientes palabras que desaparecen en las ediciones posteriores: Valentinae Academiae ... eius alumnus, non ex suo sensu, sed ex ueterum scriptorum decretis ac praesertim ex Aphthonii progymnasmatis et arte Hermogenis depromptas, quas auditoribus suis barcinonensibus anno a Chisto (sic) nato M.D.LXXVII. dictauerat, dicat alia meliora et politiora dicaturus, quum plus otii et laxamenti actus fuerit. 
sas $^{32}$, la materia que le es propia, y en esto coincide completamente con el ms. $69 \mathrm{StC}$, ya que asocia a la exornatio la gratiarum actio y la gratulatio, a la deliberación, la petitio y la consolatio y al jucio la expostulatio y la excusatio. Se establecen las partes de la retórica en Inventio, Dispositio, Elocutio y Pronuntiatio, incluida más o menos sorprendentemente, pues Núñez, como ya hemos señalado, tanto en el Commentarius (f. 84v) como en los Inst. Rhet. Lib. $V$, en el capítulo en que trata De methodo prudentiae (p. $410=438$ ), la excluye explícitamente y la considera propia de los histriones ${ }^{33}$. Vuelve a excluir la memoria explícitamente, común a todas las artes.

Divide la inventio en exordium, narratio, confirmatio, peroratio. Define el exordio como la parte del discurso en la que se prepara el ánimo del auditorio y establece las mismas partes del exordio ya establecidas en su retórica: propositio, ratio propositionis, reditio y ratio reditionis. Sin más preámbulo aborda los loci de donde se pueden tomar las rationes y propositiones de los exordios, ejemplificados con los discursos de Cicerón y sobre todo adecuados al género "exornativo", que establece en 11. Trata también los exordios según los géneros deliberativo y judicial, sirviéndose ya de la división hermogeniana de los exordios, ex opinione, ex partitione (divisione), ab exuberantia (abundantia) y ab ocasione.

A partir del f. 10 se ocupa de la narratio, excluida en el ms. $69 \mathrm{StC}, \mathrm{y}$ enumera ya al principio los cuatro loci para "dilatar" la narración: elocutio mediante la repetición e intercalación de incisos y cola, por la variedad de los hechos, por sus causas y mediante descripciones y etopeyas.

Desde el f. 13r, empieza a tratar la confirmatio. Distingue entre el género epidíctico y el forense, en el se incluyen el deliberativo y el judicial. Esa división se observa ya en la retórica impresa de 1578 y muestra la influencia de Hermógenes. En primer lugar (ff. 14v-16v) se ocupa del epidicticum genus, enumerando los objetos que pueden recibir elogio y las diferentes maneras de darle comienzo o proponerlo. Desde el f. $16 \mathrm{v}$, expone trece lugares propios para llevar a cabo la amplificatio de la laus, y a partir del f. $19 \mathrm{v}$, ya expone in extenso los loci propios de la laus personarum hasta el f. $28 \mathrm{v}$; de las cosas divinas hasta el f. $29 \mathrm{v}$; de las ciudades hasta el f. $34 \mathrm{v}$; de los animales, hasta el $34 \mathrm{r}$; y por último de los hechos y dichos memorables de personas ilustres y de las artes, hasta el f. 36r. En el f. 37r, y sin mediar ningún tipo de introducción, comienza a ocuparse de las gratiarum actiones, de su exordio, confirmatio y epílogo; de la gratulatio y sus partes; de la oratio funebris (ff. 40v-42r); y de la oratio prosphonetica (ff. $42 \mathrm{r}-44 \mathrm{r}$ ) ${ }^{34}$.

32 Oratoris officium est dicere in omni re, ea quae sunt apta ad persuadendum. Perfecti uero oratoris munus est nihil praetermittere dicendo eorum in quae insunt ad persuadendum in quaque re apta. (f. $2 \mathrm{v}$ ).

33 También es deliberadamente excluida del ms. 1657 de la Biblioteca de Catalunya: Pronuntiatio uero propria est histrionum non Rhetorum, nam Rhetores plerique habiti sunt eloquentissimi qui nihil pronuntiarunt, ut Isocrates qui nullam fertur habuisse orationem. Quare sola elocutio propria est Rhetoricae. (Ex institutionibus oratoriis Petri Johannis Nunnesii et in illas dictatas, f. $37 \mathrm{v}$ ). Por lo tanto este sería el único texto en que Núñez considera la pronuntiatio que divide en gesto y voz, una parte de la retórica y se ocupa de ella, aunque brevemente, en los folios finales del texto.

${ }^{34}$ Añade Núñez estas páginas sobre el discurso fúnebre y de recibimiento o bienvenida, pero en lo demás coincide con el ms. $69 \mathrm{StC}$. 
A partir del f. 44r. trata la causa forensis en cinco puntos: el primero quot capita summa in quaque quaestione possint inueniri, es decir que tratará sobre los status, que entiende como confirmatio del género judicial. El segundo, cómo deben proponerse estos capita. El tercero sobre la abundancia de argumentos para confirmarlos o refutarlos. El cuarto para pulir y embellecer los argumentos. El quinto y último sobre su uso más eficaz. Así pues, en los ff. $44 \mathrm{v} .-46 \mathrm{v}$. expone los status. A partir del f. $47 \mathrm{r}$ y hasta el $61 \mathrm{v}$. trata la teoría de los status con todos sus capita. Entre los ff. $61 \mathrm{v}-63 \mathrm{v}$ trata el segundo punto, sobre cómo proponer los capita de los status. Sobre su confirmación y refutación abarca el f. 64r-v.

La exornatio de los argumentos se lleva a cabo a partir de seis loci: parabola o similitudo, exemplum, maius, minus, contrarium y testimonium (ff. $64 \mathrm{v}-65 \mathrm{v}$ ). En el último punto en cuestión, sobre la eficacia de los argumentos explica la distinción hermogeniana entre argumentos propios y ficticios y el uso de entimemas y epentimemas (ff. 65v-67r).

Entre los ff. 68r-69r, se ocupa del género deliberativo y sus partes: exordium confirmatio peroratio; a partir del f. $69 \mathrm{v}$ de las partes de la consolatio; en los ff. $71 \mathrm{r}-73 \mathrm{r}$ de las formas asociadas al género judicial expostulatio y excusatio con sus partes. Entre los ff. 72r.-75r. trata del epílogo, última parte del discurso, donde expone brevemente sus partes y puntos de tratamiento ${ }^{35}$.

A la dispositio dedica apenas unas líneas entre los ff. 74v-75r.

A partir del f. $75 \mathrm{v}$, comienza la parte dedicada a la elocutio y concretamente comienza planteando cuatro cuestiones ciceronianas: cómo conseguir una oratio latina, perspicua, ornata et his rebus de quibus agitur accomodata $^{36}$.

Después de tratar los uocabula peregrina (ff. 75v-77r), se aborda la cuestión de los barbarismos y solecismos (ff. 79r-81v) y expone las características de la oratio perspicua en diez puntos (ff. $81 \mathrm{v}-82 \mathrm{v}$ ).

Entre los folios $82 \mathrm{v}-109 \mathrm{r}$, expone las figuras y tropos. Entre los ff. 109v$118 \mathrm{r}$, trata la cuestión del número, la collocatio, métrica, etc. Entre los ff. $118 \mathrm{r}-125 \mathrm{r}$, trata el período y el pneuma.

A partir del f. 125r, hasta el 146v, expone Núñez las formas de estilo o ideas de Hermógenes. Desde el f. 146v. explica cómo usar estas formas de estilo en los distintos géneros del discurso, como la oratio funebris o la panegírica.

Los dos últimos folios (154r.-155r.) los dedica a la actio que divide en voz y gesto.

El contenido de nuestro manuscrito, puede, como ya hemos señalado, atribuirse tanto a la docencia de Núñez anterior a la publicación de la Retórica de 1578 como posteriormente puesto que la práctica en el aula no tendría por qué restringirse únicamente a Hermógenes, sino que podía combinarse más explicitamente con otras tradiciones, aunque dentro de un

35 Aquí hallamos otra coincidencia con el ms. 69 StC.

36 La inspiración de esta primera parte coincide con el ms. 1657 BC De elocutione. 
marco o hilo conductor hermogeniano, como parece sugerir Fr. Alcina a propósito del ms. 1657 de la Biblioteca de Catalunya. De hecho, el primer texto de ese manuscrito, el De elocutione, aunque no es el mismo exactamente en la letra, sí comparte sus contenidos. Parece como si los materiales viajaran de unos a otros, al menos en algunas de sus partes, de modo que de la comparación entre ellos cabe deducir que, sin duda, existe una gran relación entre ellos, en el sentido de que buena parte de los contenidos del ms. $69 \mathrm{StC}$ son utilizados o reutilizados en el ms. 9153 BN, o más bien intercalados con otros materiales hermogenianos. Otros materiales, como toda la teoría de la laudatio, los vemos otra vez reelaborados en el ms. 1185 de la BUB.

Recapitulando, las coincidencias se dan 1) entre el ms. $69 \mathrm{StC}$ y el ms. $9153 \mathrm{BN}$ en el tratamiento de las subformas epistolares distribuidas entre los tres géneros retóricos; 2) entre los ms. $69 \mathrm{StC}$, el ms. $9153 \mathrm{BN}$ y el ms. 1185 BUB en el desarrollo de los tópicos o loci de género "exornativo"; 3) entre el ms. $9153 \mathrm{BN}$ y el ms. $1657 \mathrm{BC}$ en la elocutio, concretamente en la definición de las figuras antes del tratamiento de las ideae. La causa de esta inclusión en el ms. 9153 podría encontrarse en la incoherencia de la inclusión de ciertas figuras y la compositio en los capítulos del período y el pneuma en el De inventione de Hermógenes; Núñez, en sus ediciones recoloca este material en la elocutio, además el texto atribuido a Hermógenes presenta un elenco bastante incompleto de figuras que Núñez reelaboraría y completaría con materiales más tradicionales, de modo que la laguna que ofrece Hermógenes en este punto estaría en la base de la inclusión de estos materiales en un texto de inspiración hermogeniana como el ms. $9153 \mathrm{BN}$

De hecho, lo que observamos claramente en los manuscritos es el interés por el género epistolar, al que Núñez dedicaría una especial atención durante toda su vida ${ }^{37}$, y que debemos poner en relación con el hecho de que la escritura de correspondencia, tanto en ámbitos "profesionales" como personales iba a ser el género donde poner en práctica los conocimientos adquiridos, así como el énfasis puesto y la atención prestada a los loci de la laudatio en el género "exornativo", que trata en detalle en todas sus aplicaciones a personas, ciudades, las artes y demás, ya que, quizás el género encomiástico era el más adecuado para el tratamiento personal y al que mayor uso iban a dar sus estudiantes en una sociedad que había excluido el debate libre y público.

En todo caso no solo debe hablarse de la combinación de materiales diversos, sino de la utilización y selección de estos por parte de Núñez "quod et oratorem expeditiorem ad dicendum atque acriorem reddat".

37 Como demuestran sus manuscritos ya desde la primera época: "quaestio de componendis epistolis in quibus de gratiarum actione disputetur" ms. en el ejemplar conservado en el Fondo Serrano Morales del Ayuntamiento de Valencia (sg. A-6-384) de sus Institutiones oratoriae de 1552, y todas las colecciones conservadas en las diferentes bibliotecas. Para un estudio de sus impresos v. PILAR Barbeito Diez "Impresos de Pedro Juan Núñez: estudio bibliográfico." CFC. Elat, 18, 2000, 335-86. Para sus manuscritos el ya citado BARBEıTo, Pedro Juan Núñez, pp. 85-94 


\section{ABStract}

In this article Pedro Juan Núñez' ideas on rhetoric and its actual teaching at the University are examined. An evolution from the influence of Ramist rhetoric to the Hellenistic rhetoric of Hermogenes can be seen, but this evolution is consistent with Núñez' ideas on "method of teaching" in his long life as a scholar. We try to explain the practical teaching of Núñez through manuscripts on rhetoric, the combination in practice of materials from different traditions, and the adaptation of these materials to the teaching of rhetoric. 